\title{
Mapeando festas do Espírito Santo no \\ Rio Grande do Sul (Brasil) e no Quebec (Canadá)
}

\author{
Mapping the Festivals of the Holy Spirit in \\ Rio Grande do Sul (Brazil) and in Quebec (Canada)
}

Cleusa Maria Gomes Graebin ${ }^{1}$

Ilda Januário ${ }^{2}$

Submetido em 29 de novembro e aprovado em 16 de dezembro de 2019.

Resumo: Este trabalho é um relato de uma primeira tentativa para aproximar duas pesquisas paralelas sobre Festas do Espírito Santo no Grande do Sul (Brasil) e no Quebec (Canadá). No Sul do Brasil, esta celebração remonta ao século XVIII e no Quebec, à década de 1970. Nosso questionamento se direcionou para os contornos e especificidades que assumiu nestes espaços. A partir do seu mapeamento, tecemos considerações sobre sua entrada no Rio Grande do Sul e no Quebec, suas características, função social e simbólica. Percebemos que estas últimas estão relacionadas com a construção e reconstrução de identidades em diáspora e com a mediação entre o mundo dos homens e o espiritual - o do Espírito Santo. Em destaque, nestas duas pesquisas, a busca da identidade pela Festa e da autenticidade da Festa, esta última mais marcada no Brasil devido à distância no tempo e no espaço da Festa original açoriana.

Palavras-chave: Religião popular. Festas do Espírito Santo. Rio Grande do Sul, Brasil. Quebec, Canadá.

\begin{abstract}
This paper constitutes a first attempt to bring together two parallel research studies on Holy Spirit Festivals in Rio Grande do Sul (Brazil) and in Quebec (Canada). In southern Brazil, this celebration dates back to the eighteenth century and, in Quebec, to the 1970s. Our questioning was directed to the contours and specificities it assumed in these spaces. From its mapping, we make considerations about its entry into Rio Grande do Sul and Quebec, its characteristics, social and symbolic function. We realize that the latter are related to the construction and reconstruction of identities in the diaspora and the mediation between the world of men and the spiritual - that of the Holy Spirit. In the two research studies, the search for the identity and the authenticity of the festival comes to the fore, the latter being more marked in Brazil due to the greater distance in time and space relative to the original Azorean festival.
\end{abstract}

Keywords: Popular religion. Holy Spirit festivals. Rio Grande do Sul, Brasil. Quebec, Canada. 


\section{Introdução}

Como pesquisadoras, fazemos investigações sobre a presença de contingentes de açorianos no Brasil ${ }^{3}$ há 13 anos e no Canadá há $11^{4}$. Entre outros temas, temos investido nas Festas do Espírito Santo ${ }^{5}$, celebração recorrente em locais que tenham recebido a presença de contingentes de populações provenientes de Portugal continental, ou das suas ilhas, notadamente as dos Açores. Neste artigo, mapeamos e comentamos a ocorrência dessas festas no Rio Grande do Sul (Brasil) e Quebec (Canadá) investigando as suas particularidades, similitudes, transformações, bem como significados e funções sociais nesses espaços.

De acordo com Leal (1994), essa festividade é geralmente situada em Portugal no século XIV, chegando à ilha da Madeira, arquipélago dos Açores e diferentes espaços de Norte a Sul do Brasil, povoados e/ou colonizados pelos portugueses. Esse autor afirma que a "[...] vitalidade das Festas do Espírito Santo se expressa ainda no modo como, a partir dos Açores, elas se difundiram nos principais contextos de acolhimento da emigração açoriana: o Brasil, no passado, e os E.U.A. e o Canadá, mais recentemente” (1994, p. 16).

Vestígios históricos inserem a celebração ao Espírito Santo no Brasil no chamado período colonial. Abreu (1999) informa que em meados do século XVIII, têm-se rastros em Pirenópolis (GO) e Guaratinguetá (SP). Etzel (1995) defende que as primeiras Festas do Divino conhecidas, remontam a 1761 em Pindamonhangaba (SP), ou, em Salvador (BA) em 1765. Souza (2017) recua ainda mais a sua introdução, colocando-a como disseminada pelas entradas ${ }^{6}{\text { e } \text { bandeiras }^{7} \text { e indicando as folias }}^{8}$ como precursoras dos festejos do Espírito Santo pelo interior do país.

Estudando as Festas do Espírito Santo no Rio de Janeiro, realizadas entre 1830 e 1900, Abreu informa que "[...] os principais símbolos rituais da festa portuguesa e europeia são as folias, a coroação de um imperador e o império; as comemorações profanas com atos religiosos, fartura de alimentos vendidos ou leiloados, sempre preocupadas com os pobres da cidade" (1999, p. 42).

Trata-se de uma Festa que envolve diversas pessoas de uma determinada comunidade, as quais trabalham praticamente o ano inteiro (de Pentecostes a Pentecostes, pelo calendário cristão), na sua preparação. Embora tenha como foco a celebração da 
terceira pessoa da Trindade (Deus Pai, Deus Filho e Deus Espírito Santo), o sagrado se integra com o profano, ganhando diferentes elementos, dependendo dos espaços, dos sujeitos envolvidos e de sua função social, constituindo-se como excelente laboratório para observarmos as diversidades culturais e peculiaridades de suas trajetórias históricas locais. No entanto, todas têm como eixo transversal a fé no Espírito Santo e o agradecimento por dádivas alcançadas. Neste sentido, concordamos com Gonçalves (2008) e Leal (1994) quando afirmam que as atividades são permeadas por dádivas e contradádivas de diferentes naturezas.

\section{Festas do Espírito Santo no Rio Grande do Sul (Brasil)}

Os contingentes de casais de número ${ }^{9}$ vindos dos Açores começaram a chegar ao Rio Grande do Sul a partir de 1752 (referencial cronológico), por meio de uma política da Coroa portuguesa para a povoação e a colonização do Sul do Brasil. Sua entrada deu-se pelo porto da então Vila do Rio Grande, alcançando paulatinamente outros espaços, dando origem a diversas cidades sul-rio-grandenses. Essas foram marcadas pela presença dos ilhéus, traduzindo-se na arquitetura, na produção têxtil, nas práticas agrícolas (hortaliças, frutas e legumes), na religiosidade, na literatura oral (adágios, adivinhas e trovas), entre outros.

Em se tratando da religiosidade, o culto ao Espírito Santo transmigrado das Ilhas para o Rio Grande do Sul no século XVIII, constituiu-se como instrumento de inserção dos açorianos, bem como, ao longo do tempo, como elemento de construção identitária. A celebração ocorre em vários municípios, como informa Paixão Côrtes (1983), memorialista e folclorista sul-rio-grandense que, em exaustiva pesquisa, cartografou as devoções, festas e outras manifestações pelas comunidades rurais e urbanas do Rio Grande do Sul. Santo Antonio da Patrulha, Osório, Gravataí, Taquari, Rio Pardo, Triunfo, Porto Alegre, Viamão, Mostardas, São José do Norte, Rio Grande, São Lourenço, Caxias do Sul, Caçapava do Sul, Vacaria, Bagé, Jaguarão, entre outras, são cidades em que ocorrem as Festas do Espírito Santo.

No século XIX, segundo Côrtes (1983), a Festa era um dos momentos mais importantes entre os eventos religiosos do Rio Grande do Sul. A primeira Irmandade do Divino Espírito Santo foi fundada na capital, Porto Alegre, em 1821. 
Contemporaneamente, no interior do Rio Grande do Sul, as Festas começam a ser preparadas logo após o carnaval, quando se reúne o grupo de festeiros, liderados por um padre, pelo Imperador e Imperatriz. A partir da Páscoa iniciavam as visitas da Bandeira pelas casas de fiéis de uma localidade, ritual que integra a sua passagem por todos os cômodos da casa, com momentos de orações, pedindo graças e agradecendo àquelas alcançadas. De acordo com Dreher, “[...] as bênçãos trazidas pela Bandeira do Divino eram indispensáveis para o bom sucesso da vida familiar [...]" (2002, p. 19). Por vezes, a Bandeira é levada por uma comitiva de músicos e cantadores (a Folia) que, a partir de louvações, prestam honrarias ao Espírito Santo: “a Bandeira do Divino vai/entrar nesta morada, ai, ai!/Visita a sua casa/ pra que seja abençoada ai, ai!” (HASTENTEUFEL, 1998, p. 170). Em alguns lugares com características rurais, a comitiva é formada pelas chamadas cavalgadas, tropa de homens (e também de mulheres) a cavalo que se deslocam por diferentes espaços.

A Festa propriamente dita, em geral, abrange um período de dez a doze dias, iniciando com a elevação do mastro, a novena ou tríduo do Divino, missas e procissão. Em algumas das suas versões, a coroação do imperador e da imperatriz dá-se na própria igreja durante uma missa. Estes acompanham uma procissão e, em alguns casos, ocorre uma espécie de banquete ou distribuição, ao término da festa, de pequenos pães em formato de pomba para todos os fiéis presentes. Também pode ser acompanhada de cavalgadas (caso de Vila Seca) ou de Cavalhadas (encenação de luta entre mouros e cristãos), como em Mostardas. É possível perceber, também, “[...] que o culto ao Espírito Santo se expressa como forma de devoção ou obrigação institucionalizada, como herança deixada pelos antepassados" (GRAEBIN, 2012, p. 17).

Entre os elementos que compõem a Festa temos: a coroa, estandartes ou bandeiras, peditório, novenas ou tríduos, imperador, imperatriz, festeiros, cortejo, folias, mastro, os pães, almoços e/ou banquetes. Em alguns lugares, coroa-se uma criança ou adolescente e, em outros, homens e mulheres adultos ou idosos. Mesmo com supressões ou inserções de elementos na sequência ritual, sua função social está relacionada a processos de construção identitária, principalmente em cidades com forte presença açoriana na sua origem, com descendentes buscando como coloca Gonçalves, "[...] articulação social e 
simbólica dessa população no plano local (do bairro, da cidade), assim como em planos extralocais [...]" (2008, p. 73).

No Quadro 1 a seguir, mapeamos algumas das Festas do Espírito Santo no Rio Grande do Sul e suas características. Tendo em vista a quantidade dos festejos, optamos por apresentar aquelas que trazem elementos diferenciados.

\section{Quadro 1 - Festas do Espírito Santo no Rio Grande do Sul (Brasil) (2018)}

\section{Cidade Informações sobre a festa do Espírito Santo}

Criúva
$\begin{aligned} & \text { A Festa do Espírito Santo } \\ & \text { iniciou com a criação da } \\ & \text { Paróquia N. }{ }^{a} \text { Sr. do Carmo, em } \\ & \text { 1924. Após uma interrupção, } \\ & \text { desde 1971, os festejos foram } \\ & \text { retomados com novenas, visitas } \\ & \text { às famílias, em torno de dois } \\ & \text { meses antes do evento maior. A } \\ & \text { preparação inicia já no mês de } \\ & \text { fevereiro com o envio das } \\ & \text { Bandeiras do Divino para as } 15 \\ & \text { comunidades da Paróquia. } \\ & \text { Existe uma equipe de louvação } \\ & \text { formada por festeiros, padres e }\end{aligned}$
músicos, que visitam as residências, estabelecimentos comerciais
e industriais, órgãos de governo e imprensa, levando bênçãos e
divulgando a Festa. O ápice se dá no mês em que se celebra o
Pentecostes, quando ocorrem as novenas, missa festiva campal,
jantar, baile, procissões, sorteio do queijo, leilão de animais e a

Jaguarão

A Festa ocorre na Paróquia do Divino Espírito Santo, iniciando com a visita da "Folia do Divino", rememorando momentos das festas passadas. Ocorrem novenas, inauguração do mastro e colocação da Bandeira no Largo em frente à igreja. À noite, durante o período dos festejos, as comunidades são visitadas por pregadores. No dia da festa, ocorre a procissão, um almoço beneficente ao meio dia, quermesse comunitária, diversas atrações culturais no Largo das Bandeiras e missa festiva à noite. 
Mostardas A Festa inicia com a elevação do mastro. Nove dias antes da festa, à tarde, sai, da casa do festeiro, um préstito, antecedido por banda de música. Dali vão até, a casa do Alferes e, de lá, para a igreja onde o padre benze a Bandeira. Os homens na igreja vestem as opas da Irmandade do Divino. São feitos os tríduos, cortejos com o festeiro carregando a coroa, com 6 pessoas carregando tochas. Na véspera da Festa ocorre o "tirar a esmola" com a presença do festeiro, banda, alferes e espadim, percorrendo a cidade. No dia da Festa o cortejo dirige-se ao Império para buscar a Coroa e a Bandeira. Daí se dirigem à igreja, onde é realizada a missa festiva. Após, realiza-se um banquete ou churrasco com a participação da comunidade. À tarde, ocorre a procissão. Na frente a cruz, escoltada por dois membros da irmandade com opas e lanternas. Entre as filas vão as bandeiras das congregações. Vêm então, os homens: num andor é levada, por quatro homens com opas, a imagem do divino: a pomba branca; é parecida a um ostensório e feita de madeira. Precedem-na as bandeiras; segue o grupo de festeiros. $\mathrm{O}$ vigário vai na frente do Divino, a banda de música atrás. Percorre a procissão as ruas principais da cidade e volta para a igreja onde se dissolve.

Osório A Festa ocorre na Catedral de N. ${ }^{a}$ Sr. ${ }^{a}$ da Conceição com novenas, apresentações culturais de corais, Folias do Divino e Tropeiros, grupos de dança, Orquestra de Sopros e Missa Crioula. O ápice está na procissão, na Missa festiva e no almoço no salão paroquial.

A Festa limita-se à semana de Pentecostes, com novena, dentro da própria igreja e uma procissão no domingo, com um roteiro que integra uma série de ruas da cidade, saindo da Catedral até a Igreja do Divino Espírito Santo. O cortejo é formado da seguinte maneira: a frente vem a cruz, com os lanterneiros (membros da Irmandade do Espírito Santo); após, o arcebispo metropolitano e atrás deste, os padres convidados, juntamente com o pároco da Igreja do Espírito Santo; na sequência vêm os membros da Irmandade, os provedores, os festeiros, o alferes da bandeira, os grupos de oração que atuam dentro da própria igreja do Divino com suas bandeiras, seus estandartes próprios; os devotos com bandeiras do Divino, tanto os que cumprem promessas ou os que compram da Irmandade, o direito de carregar bandeiras durante a procissão. Por último, fieis que acompanham o cortejo. No destino - a Igreja do Divino Espírito Santo - , há o encerramento com uma missa solene, finalizada com a coroação, pelo Arcebispo, de um Imperador Festeiro e pela passagem da Bandeira para o novo Alferes, os quais serão os responsáveis pela próxima Festa. 


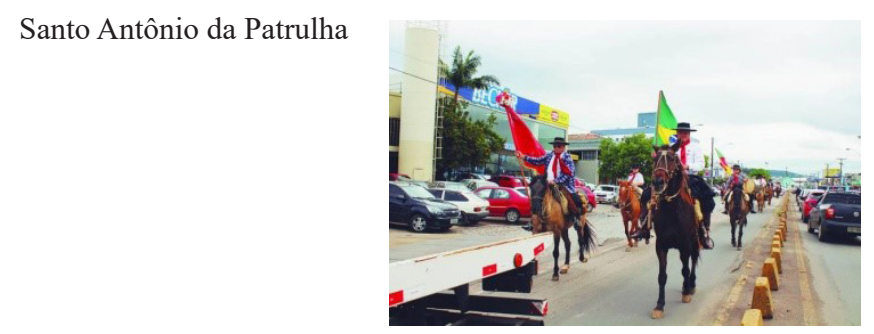

A Festa é realizada na Paróquia de Santo Antônio fundada há mais de 240 anos. Envolve personagens como festeiros e festeiras, mordomos e aias. Inicia com cavalgada em que participam os Tropeiros

do Divino e cavalarianos, percorrendo boa parte da cidade, finalizando com Missa Crioula campal. Ocorrem festejos populares, almoços festivos, sopão do Espírito Santo ofertado às comunidades carentes, missas e eventos culturais.

São Lourenço do Sul

A festa é realizada na comunidade da Imaculada Conceição do Boqueirão, há mais de 100 anos. Ocorrem as novenas e, ao término, há a bênção para as famílias, jovens e crianças; para pães, óleo e objetos religiosos, todos simbolizando a vida e a fartura. Ocorrem também, shows musicais e jantar- baile. No dia da festa, propriamente dita há uma missa festiva pela manhã, e ao meio dia haverá almoço com churrasco. À tarde continuam os shows, feira de produtos agrícolas, industriais e artesanais.

Fontes: http://www.portaldodivino.com/Brasil/RioGrandedoSul/rs.htm/ http://mostardasvirtual.blogspot.com/2009/05/festa-do-divino.html 
A título de ilustração, trazemos a seguir, imagens da festa em Vila Seca e Gravataí.

Figura 1: Festa do Espírito Santo em Vila Seca, Caxias do Sul), RS (2007).

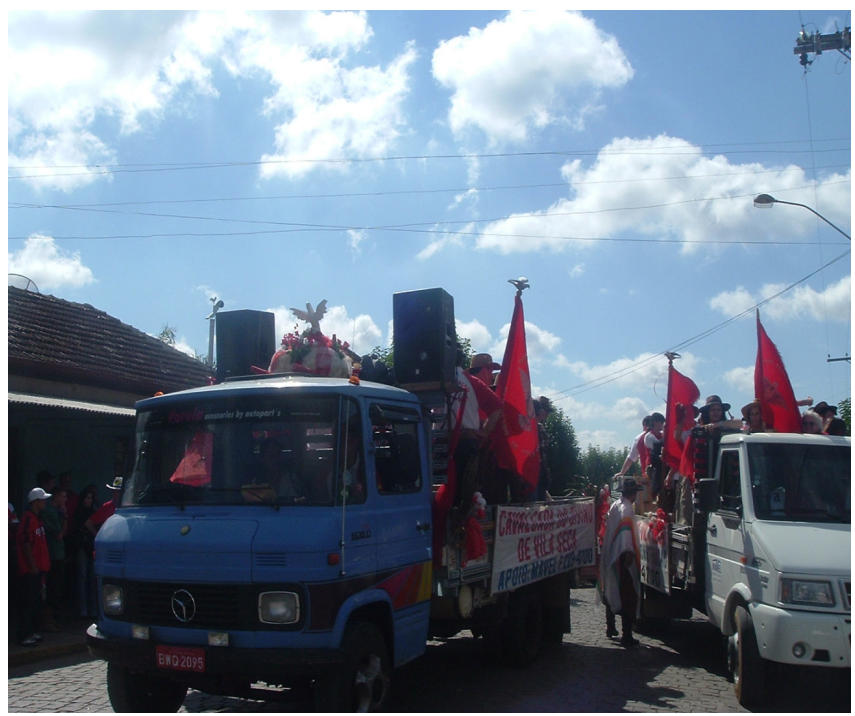

Fonte: Acervo de Cleusa Maria Gomes Graebin.

Figura 2: Festa do Espírito Santo em Gravataí (2007)

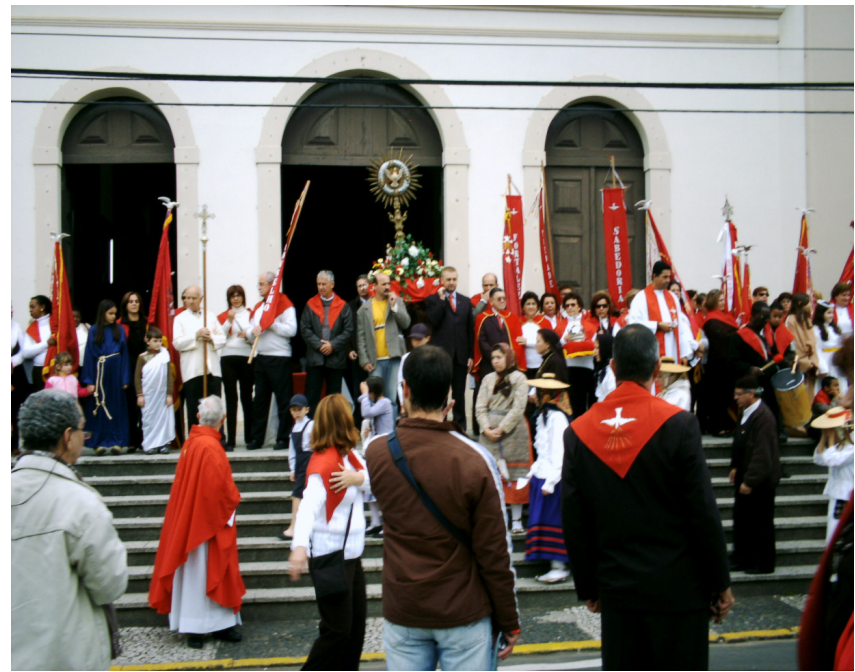

Fonte: Acervo de Cleusa Maria Gomes Graebin 
De acordo com os dados levantados sobre as Festas do Espírito Santo no interior do Rio Grande do Sul, percebe-se que estas guardam uma sequência ritual da celebração muito próxima daquelas que ocorrem nas Ilhas dos Açores, com os acréscimos decorrentes dos processos históricos regionais e dos "saberes e fazeres" das diferentes etnias que povoaram o estado. Enquanto em Santo Antonio da Patrulha, município de colonização luso-açoriana - antigo posto de passagem de tropas de gado muar, cavalar e bovino faz-se cavalgada de tropeiros, em Criúva, de colonização italiana, um dos momentos mais esperados é o sorteio do queijo gigante, preparado especialmente para a ocasião.

Destaca-se que a capital do estado, Porto Alegre, formada a partir da presença de contingentes luso-açorianos, teve em sua Festa do Espírito Santo, um dos pontos altos das celebrações religiosas. Segundo Arsène Isabelle, as Festas do Divino Espírito Santo, em 1834, eram celebradas “com pompa [...]. As sacadas são guarnecidas de ricos tapetes de seda bordada com franjas de ouro; as confrarias azuis sucedem-se às vermelhas, estas às brancas, e estas às cinzas, etc. Cada uma leva relicários de santos, suntuosamente ornados, e depois, durante três dias, vendem-se publicamente, ao lado da igreja, rosários, escapulários, galinhas assadas, pastéis, licores, etc. [...] (1983, [1834], p. 62-64).

O espaço da Festa em Porto Alegre era a praça central, onde estava a Catedral e a Capela do Divino (Figura 3). 
Figura 3 - Festa do Espírito Santo em Porto Alegre (Década de 1900).

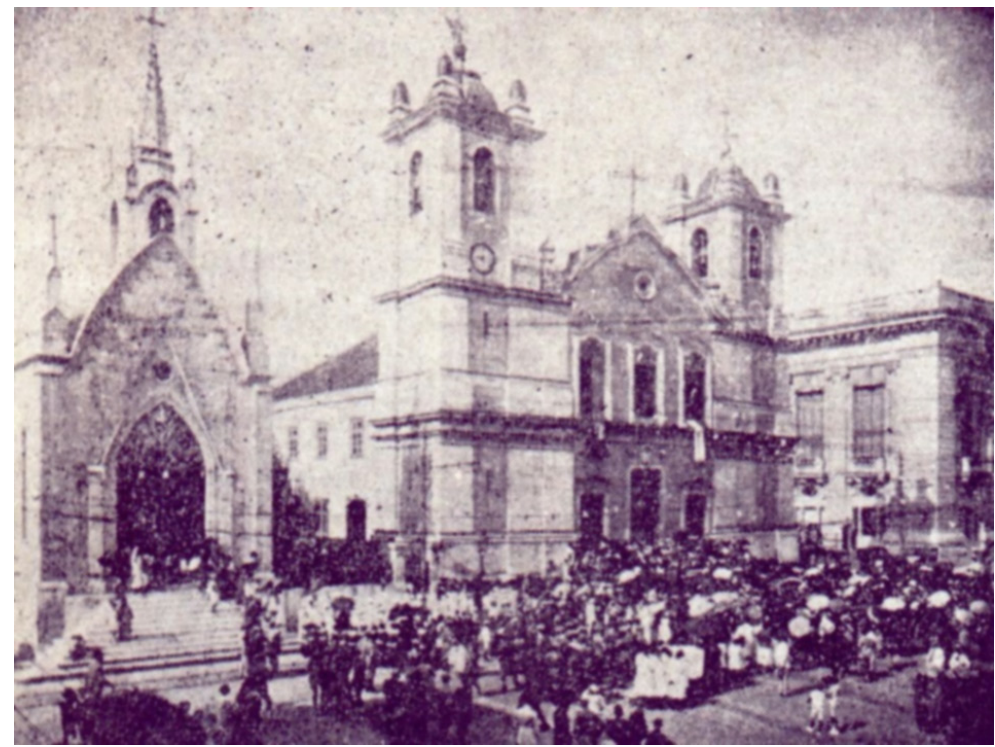

À esquerda a Capela do Espírito Santo ao lado da antiga catedral. Fonte: Museu Histórico la Salle.

A celebração envolvia o levantamento do mastro, a presença de coretos para apresentação de bandas, os peditórios no seu entorno, com as casas devidamente preparadas para receber a Bandeira, o foguetório, as novenas, a coroação do imperador, as tendas para a venda de bebidas e alimentos. Ocorriam bailes e leilões das dádivas recolhidas durante as visitas da Bandeira, com um grande número de fieis que acorriam à cidade, vindos dos mais diversos recantos.

[...] a capela do Espírito Santo não se abria senão quando começavam as novenas e tinha início o peditório das bandeiras. Ficava aberta durante este e os ' fogos', atraindo os fieis de todos os matizes sociais. [...] Logo que os jornais anunciam o 'peditório', a pobreza da cidade se agita. 'Pobreza', aqui quer dizer — as camadas desfavorecidas da fortuna formadas por essa imensa legião de operários e trabalhadores que formam mais de dois terços da Humanidade (PORTO ALEGRE, 1940, p. 94-95).

A distribuição de donativos aos carentes era realizada com acompanhamento de banda de música. Em 24 de maio de 1895, uma matéria jornalística criticava este costume: 


\begin{abstract}
Ora, não seria mais sensato, digno e respeitável que poupasse aos pobres a exibição de sua miséria, de baixo de música, distribuindose as esmolas sem aparato? A miséria envergonha e é um martírio para muitos desgraçados ir debaixo de ruidoso aparato receber um óbolo; a verdadeira caridade cristã é essa? Mais valeria que a comissão de festejos tivesse a sua lista de miseráveis confeccionada e mandasse levar a cada um deles o seu quinhão, isto sem ruído, sem ostentação, coisas ridículas e dignas de uma vaia (GAZETA DA TARDE, p. 2).
\end{abstract}

Sobre esta prática Aquiles Porto Alegre informa: "Logo que os jornais anunciam o 'peditório', a pobreza da cidade se agita. 'Pobreza', aqui quer dizer — as camadas desfavorecidas da fortuna formadas por essa imensa legião de operários e trabalhadores que formam mais de dois terços da Humanidade" (1940, p. 94-95).

A partir da década de 1860, com a ação do Bispo Dom Sebastião Dias Laranjeira, iniciou uma espécie de disciplinamento dos costumes dos crentes nas festas de santos, tanto no proceder dentro das igrejas, como nas procissões, novenas e tríduos. Uma de suas estratégias foi a aproximação com as Irmandades, mantendo-as sob seu controle. De acordo com Nascimento, o Bispo exigia-lhes “[...] que se enquadrassem aos novos princípios da disciplina cristã, arrancando, a partir da raiz, o que estas tinham de mais original e autêntico, sua autonomia sobre as festas e disposições nas demais cerimônias religiosas" (2006, p. 55). Ainda segundo esta autora, Dom Sebastião proibiu festejos e missas nas igrejas durante a noite, normatizou as celebrações e estabeleceu punições para os desobedientes. Uma das obrigatoriedades era a da presença dos sacerdotes com as vestes mais pomposas, usadas nas celebrações mais solenes, esvaziando a suntuosidade das vestes das confrarias.

As Irmandades tiveram reguladas a sua presença nas procissões, ocupando os espaços atrás das autoridades eclesiásticas. Paulatinamente, a Festa em Porto Alegre foi perdendo ser caráter de festejo popular, notadamente após a proclamação da República, quando as sociabilidades se modificaram e novas posturas municipais foram impostas. De um cristianismo leigo com a inserção de diferentes devoções, passou-se a valorizar o aspecto sacramental, fidelidade e fervor religioso, com a vida privada e pública devendo ser regidas por princípios católicos, com o clero controlando as Irmandades, as festas, os cultos religiosos e os costumes dos crentes (DREHER. 1998). Na Festa da capital, 
podemos observar, na descrição da sequência ritual, no Quadro 1, os elementos da "reforma” de Dom Sebastião Dias Laranjeira.

\section{Festas do Espírito Santo no Quebec (Canadá)}

A primeira vaga migratória açoriana para a América do Norte teve lugar entre 1870 e 1930, para a Califórnia e a Nova Inglaterra, nos Estados Unidos. Os emigrantes açorianos levaram as Festas para a Califórnia, a partir dos anos 1880. Foi na segunda vaga, entre os anos 1950 e 1980, que os açorianos passaram, também, a imigrar para a Bermuda e Canadá (Leal, 2017).

Somavam no Canadá, por origem étnica, 482605 luso-canadianos e lusodescendentes, dos quais 324930 no Ontário (67\%), 69805 no Quebeque (14\%), 41 770 (9\%) em Colúmbia Britânica (Censo, 2016). Entre 60-70\% são açorianos e vivem em maior concentração em Toronto, Montreal e Vancouver, por essa ordem, maioritariamente oriundos das ilhas de São Miguel, Terceira e Pico.

Segundo Leal (2017), 290 Festas anuais foram contabilizadas na América do Norte, 201 nos Estados Unidos e 87 no Canadá. Por província: 59 no Ontário, 11 no Quebeque, sete (7) na Colômbia Britânica, sete (7) em Alberta, e três (3) em Manitoba. No Canadá, as seis Festas mais antigas datam dos princípios e meados dos anos 1960, sendo a primeira de Cambridge, Ontário, criada em 1962. Dois terços das Festas foram fundadas nos anos 1970 e 1980 e apenas 19 nos anos 1990. A última criada foi em Brampton, Ontário, em 2013, por uma irmandade de igreja.

Tanto no Canadá como nos Estados Unidos, dois terços das Festas são promovidas por irmandades independentes (42\%), por clubes/associações ou, ainda, por bandas filarmónicas (25\%); e um terço por irmandades de igreja em paróquias designadas portuguesas (32\%). A notar, no contexto migratório, o papel acrescido da igreja, clube/ associação ou banda filarmónica, na organização das Festas, relativamente ao do mordomo nas ilhas (Leal, Januário, Mapril, 2014; Leal, 2017), o que contribuiu para “democratizar” o acesso à mordomia da Festa.

A sequência ritual da Festa, não obstante algumas diferenças que derivam da origem regional dos organizadores e da área em que se estabeleceram no Canadá, por 
exemplo acesso a fazendas rurais, é bastante consistente, tendo-se tornado generalizado o ritual das sopas servidas à comunidade no dia da Festa (e não só aos familiares e convidados do mordomo) e a compra, pelos "irmãos" de "pensões", ou "esmolas", e constam de uma quantidade de carne, vinho, pão e massa sovada (doce). As pensões de “criador" incluem quantidades maiores destes géneros e alguns extras. O criador é quem oferece ao mordomo ou à comissão da irmandade, uma quantidade maior de carne (o item mais caro da comensalidade) ou o equivalente em dinheiro. A sequência ritual da Festa é a seguinte:

\section{a) Culto privado e festas de angariação de fundos durante o ano:}

- A Coroa e a Bandeira do Espírito Santo circulam entre as casas dos irmãos para a reza do terço entre família e amigos. Esta prática intensifica-se durante as 6 ou 7 “domingas" que mediam entre a Páscoa e domingo de Pentecostes ou de Trindade; - Fazem-se de duas a quatro festas de angariação de fundos nas irmandades, clubes e igrejas, durante o ano; ou tem lugar um peditório de porta a porta;

- Mais raramente, dá-se o gado oferecido a criar em fazendas ou "farmes" e faz-se o vinho.

\section{b) Culto público e dispêndio dos fundos: preparativos e Festa grande ou Bodo}

- Decoração dos lugares públicos e montagem dos altares ou "quartos" do Espírito Santo.

- Compra e preparação das carnes, vinho, pão, massas e ingredientes para as sopas.

- Busca de patrocínios, em gêneros e donativos, de particulares e comerciantes.

- Apresentações e arrematações de gado.

- Ceia dos criadores.

- Coroações das famílias das domingas.

- Entrega ao domicílio, ou levamento de pensões na sede ou igreja da irmandade (na sexta-feira e sábado) seguidos de ceia de carne guisada e entretenimento.

- Reza do terço em casa do mordomo, na associação ou igreja, durante a semana.

- Procissão ou cortejo da coroação no domingo, seguida de sopas comunitárias, arrematações e rifas de géneros e objetos doados, seguidos de arraial. 
- Seleção do novo mordomo, pela entrega da Bandeira. Ele foi escolhido anteriormente, acaso tenha promessa, ou é escolhido no momento, por impulso ou inspiração divina.

\section{c) Depois da Festa:}

- Procede-se à limpeza e arrumação do local da festa e o mordomo "velho" agradece à comissão e ajudantes com uma lembrança e uma lauta refeição.

- O mordomo "novo" começa a recrutar sua equipa de voluntários, a planejar festas de angariação de fundos durante o ano e a procurar patrocínios.

Os organizadores das Festas são imigrantes de primeira geração, com alguma participação da segunda, voluntários com quarenta e mais anos de idade, a que se juntam cerca de $10 \%$ de jovens fora dos dias da Festa grande.

Na província de Quebec, quatro Festas foram criadas nos anos 1970, três na década seguinte e quatro nos anos 1990. Existiam oito Festas de organizadas por associações (três de cariz terceirense) e três por comissões de Festas ligadas à igreja. Onze Festas foram identificadas em 2010-2011 que se distribuem em três grupos: as que têm lugar nas ilhas de Montreal e de Laval, as de periferia destas duas ilhas-cidades e, ainda, as de Gatineau e Aylmer, a oeste da província, perto do Ontário, estudadas em 2013.

Para as Festas na periferia - Sainte-Thérèse, Blainville e West Island - e a da Casa dos Açores do Quebeque (Açorbec), em Montreal, as coroações têm lugar na igreja local, que é francófona, presidindo à missa da coroação um de dois padres quebequenses que falam português, se não estiver disponível um dos dois párocos portugueses que serviam as comunidades maiores: Montreal, Anjou, Hochelaga e Laval. Nestas Festas eram servidas, nos anos da pesquisa, sopas entre 600 a 1000 comensais e, em Anjou, a cerca de 2 000, num pavilhão desportivo arrendado, entre a carne guisada no sábado e as sopas no domingo.

Dado o pequeno número de Festas relativamente ao do Ontário, existe um “acordo de cavalheiros" para as Festas terem lugar em sequência em vez de se concentrarem nos domingos de Pentecostes e de Trindade, respectivamente o sétimo e oitava domingos 
depois da Páscoa. Algumas têm lugar nas datas mais próximas das festas de S. João Baptista (as terceirenses) e de S. Pedro (as micaelenses), terminando, o mais tardar, a meados de julho. Efetivamente, o terço de uma Festa que começa é rezado na segundafeira que segue o domingo da Festa que acabou.

Entre a Páscoa e os domingos de Pentecostes e Trindade, têm lugar as seis ou sete "domingas", termo micaelense, em que coroam as pessoas que, durante o ano, se ofereceram, mediante sorteio no fim da Festa, para ir a coroar num desses domingos. $\mathrm{O}$ ritual da coroação no tempo das domingas deve-se ao terem alojado a Coroa e a Bandeira do Espírito Santo para o culto doméstico durante pelo menos uma semana.

Devido à origem do culto em Portugal continental, e sua migração para as ilhas dos Açores pelas mãos dos franciscanos, que tiveram o apoio do casal real formado por D. Dinis e D. Isabel, a Coroa passou a ser usada nas festas portuguesas do Espírito Santo a par da Bandeira e da Pomba. No Quebec, número de coroas da associação ou igreja pode ir até cinco.

Dado o número importante de terceirenses no Canadá, outras práticas que se encontram nas suas Festas são o "pezinho de bezerro", ou cantorias ao desafio, e o "bodo de leite", em que se distribui massa doce e leite; e sopas servidas com alcatra, na Festa grande (que os terceirenses chamam de Bodo) para além da travessa com carnes cozidas, cujo caldo constitui a base das sopas.

Atendendo a que as Festas seguem a mesma sequência ritual, passarei a dar uma listagem de cada Festa no Quebec por ordem cronológica de fundação, assinalando algumas das características que as distinguem. 


\section{Quadro 2 - Festas do Espírito Santo no Quebec (Canadá)}

\begin{tabular}{|c|c|}
\hline Cidade ou Vila & $\begin{array}{l}\text { Nome da irmandade, império, mordomia ou comissão da } \\
\text { Festa }\end{array}$ \\
\hline Gatineau & $\begin{array}{l}\text { COMISSÃO DE S. PEDRO DO CENTRO COMUNITÁRIO } \\
\text { PORTUGUES AMIGOS UNIDOS foi criada em 1974, a } \\
\text { mais antiga no Quebec que ainda existe, e é assim chamada } \\
\text { por a Festa ser celebrada perto da data do santo, no feriado } \\
\text { nacional do } 1^{\circ} \text { de julho. Os } 12 \text { membros da Comissão são } \\
\text { considerados mordomos. A Festa é celebrada com cunho } \\
\text { micaelense e terceirense. }\end{array}$ \\
\hline Laval & $\begin{array}{l}\text { FESTA DO ESPÍRITO SANTO DA MISSÃO DE NOSSA } \\
\text { SENHORA DE FÁTIMA DE LAVAL foi criada em 1978, a } \\
\text { primeira em Montreal-Laval e ainda a maior, que celebra no } \\
\text { domingo de Trindade. Um cortejo etnográfico tem lugar no } \\
\text { sábado - uma iniciativa inspirada nas Festas de Fall River } \\
\text { nos EUA. }\end{array}$ \\
\hline Sainte-Thérése (vila) & $\begin{array}{l}\text { IMPÉRIO DE S. PEDRO foi criado em 1978, pela Associação } \\
\text { Portuguesa de Sainte-Thérèse, e tem lugar no fim de semana } \\
\text { do } 1^{\circ} \text { de julho. A particularidade deste império é o fato de a } \\
\text { mordomia ter sido assumida, seis vezes, por mulheres jovens, } \\
\text { desde } 2001 \text {. }\end{array}$ \\
\hline Montreal & $\begin{array}{l}\text { FESTA DO ESPÍRITO SANTO DA MISSÃO DE SANTA } \\
\text { CRUZ, criada em 1979, é a primeira Festa no calendário a } \\
\text { ser celebrada em Montreal, a Pentecostes. É a Comissão das } \\
\text { Grandes Festas que se ocupa de contratar a banda filarmônica } \\
\text { e de comprar e distribuir as } 500 \text { pensões, sendo o mordomo } \\
\text { financeiramente responsável pela Festa. O padre aceitou ser } \\
\text { mordomo, em } 2008 \text {. }\end{array}$ \\
\hline $\begin{array}{l}\text { Montreal (bairrode Hochelaga- } \\
\text { Maisonneuve) }\end{array}$ & 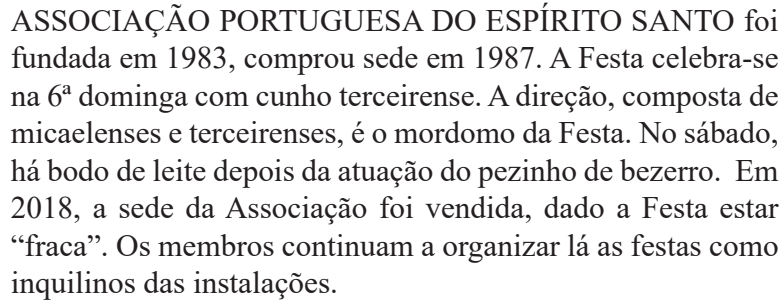 \\
\hline
\end{tabular}




\begin{tabular}{|c|c|}
\hline Montreal (bairro de Anjou) & $\begin{array}{l}\text { CENTRO COMUNITÁRIO DO ESPÍRITO SANTO } \\
\text { D'ANJOU registrou-se com o nome atual em 1985, após a } \\
\text { compra da sede. A Festa do Centro era a quinta agendada } \\
\text { no calendário das Festas do Espírito Santo de Montreal. A } \\
\text { direção paga as despesas que o mordomo não consiga pagar, } \\
\text { como o aluguer do pavilhão desportivo para o fim de semana } \\
\text { da Festa, dado ser esta a maior Festa de Montreal. No ano } \\
\text { da pesquisa, ela foi promovida por uma jovem, que assumiu } \\
\text { sozinha as despesas. }\end{array}$ \\
\hline Blainville (Vila) & $\begin{array}{l}\text { ASSOCIATION DES ENFANTS PORTUGAIS ET } \\
\text { CANADIENS DE BLAINVILLE (IMPÉRIO DAS } \\
\text { CRIANÇAS). Criado em 1987, é um império de cariz familiar, } \\
\text { micaelense e terceirense. Cresceu o número de jovens de } \\
\text { segunda geração que participam. Era presidente da direção, } \\
\text { um jovem nascido no Quebec, e o mordomo era outro jovem } \\
\text { da mesma família. O mordomo sobe de impulso ao palco para } \\
\text { pegar na Bandeira. }\end{array}$ \\
\hline Aylmer (Gatineau) & $\begin{array}{l}\text { FESTA DO ESPÍRITO SANTO DA ASSOCIAÇÃO } \\
\text { CULTURAL PORTUGUESA DE AYLMER foi criada em } \\
1993 \text { e desativada em 2014. Os membros eram oriundos de } \\
\text { S. Miguel e da Terceira. A Associação foi comprada com as } \\
\text { receitas geradas pelo império que a antecedeu. A Festa era } \\
\text { organizada por um mordomo independente até } 2011 \text { e pela } \\
\text { Associação em 2012-2013. Devido ao envelhecimento da } \\
\text { pequena comunidade, foi vendida. O dinheiro foi distribuído } \\
\text { por instituições de saúde e banco alimentar. }\end{array}$ \\
\hline Gatineau & $\begin{array}{l}\text { MORDOMIA DA MISSÃO CATÓLICA PORTUGUESA DO } \\
\text { ESPÍRITO SANTO DE GATINEAU foi criada em 1995. A } \\
\text { Festa da Missão celebra-se meados de julho e encerrar o ciclo } \\
\text { das Festas na área. O número dos mordomos varia entre } 12 \text { e } \\
15 \text {, aos quais se juntam } 10 \text { pessoas da comissão (micaelenses, } \\
\text { terceirenses e jorgenses). Levantam-se as pensões e reza-se o } \\
\text { terço na igreja, faz-se o bodo de leite e a procissão de domingo } \\
\text { tem carros alegóricos. }\end{array}$ \\
\hline West Island & $\begin{array}{l}\text { FESTA DO ESPÍRITO SANTO DA ASSOCIAÇÃO } \\
\text { PORTUGUESA DE WEST ISLAND foi criada em } 1996 \\
\text { e desativada em 2018, dois anos depois do fecho da } \\
\text { Associação, cujas instalações eram alugadas. Era uma Festa } \\
\text { com sequência ritual completa, se em pequena escala, com } \\
\text { mordomo, domingas, distribuição de pensões, reza de terço e } \\
\text { sopas, faltando apenas a procissão da coroação para a igreja, } \\
\text { para onde se ia de carro. }\end{array}$ \\
\hline
\end{tabular}


Montreal

FESTA DO ESPÍRITO SANTO NA CASA DOS AÇORES

DO QUEBEQUE, criada em 1999, é a primeira no calendário das Festas de Montreal-Laval, em tempo das domingas. A Festa não segue a sequência ritual completa e consiste apenas numa dominga com coroação na igreja, seguida de sopas na sede. O terço reza-se durante a semana e é seguido de convívio; o bazar abre no primeiro dia e fazem-se arrematações. No sábado, serve-se o jantar de carne guisada, acompanhado de uma atuação dos foliões.

Fonte: Irmãos e Irmãs na Coroa. As Festas do Espírito Santo no Canadá.

Eram 11 as Festas no Quebec nos anos em que foram pesquisadas entre 2010 e 2013, fundadas quase todas no fim dos anos 1970. Atualmente são nove (9) as Festas, depois de desativadas, em 2014 e 2018, as Festas da Associação Cultural Portuguesa de Aylmer e da Associação de West Island. Como no resto do país, cerca de dois terços das Irmandades no Quebec tiveram origem independente, sendo apenas três de igreja.

A Arquidiocese de Montreal não tem estatutos sobre as Festas do Espírito Santo, como é o caso da Arquidiocese de Toronto. A inovação no Quebec é que os quatro padres portugueses foram mordomos da Festa. Ambas as situações - o padre presidente da irmandade de igreja, no Ontário, ou mordomo da Festa, no Quebec - são inéditas na história das Festas do Espírito Santo tanto nas ilhas como em contexto migratório.

É comentado o contraste entre o modelo da mordomia existente em Santa Cruz e o de outras Festas. Nesta paróquia, o mordomo, apesar de não ter o encargo completo da Festa, faz nela um investimento financeiro considerável, que depois oferece à igreja, após descontadas as despesas. Apenas o recupera se tiver, além de boa situação econômica, bom número de relacionamentos na comunidade que se traduzem em donativos e outros tipos de ajuda.

Em Laval, apesar de o modelo da Festa se comparar com o de Santa Cruz dado que as coletas e os arrendamentos das salas da igreja não bastam para manter as igrejas, e ambas as Festas são muito lucrativas -, é, em última análise, sobre o "conselho econômico" que recai o encargo da Festa, que também arrecada as receitas depois de pagas as despesas. O que varia é a escala das despesas que recaem sobre 
o mordomo. O modelo de West Island era como o de Santa Cruz, embora em escala muito menor.

Nas Festas de periferia, há a registrar que duas são de cariz familiar: SainteThérèse e Blainville. Em ambas, havia um número considerável de jovens na comissão ligados por laços de parentesco, sobretudo em Blainville.

As questões de gênero são mais notórias nas equipas de cozinha, na organização das tarefas e na mordomia. Pelo menos duas equipas masculinas estavam encarregadas da carne guisada e das sopas: em Laval (marienses), West Island, Sainte-Thérèse e Blainville. Em várias associações e na igreja de Laval e na missão de Gatineau, as mulheres tinham um papel de destaque na direção da comissão de Festas e na organização delas. Em Aylmer, foram elas que fundaram o Império da Caridade e que, em maioria, administraram a Associação.

Apenas no Quebec se constatou o fenômeno inovador das imperatrizes, jovens de segunda geração, algumas separadas e com filhos, que assumem sozinhas a mordomia. Começou em Sainte-Thérèse (entre 2001 e 2011), mas também se verificou em Santa Cruz (2009) e em Anjou (2010), enquanto no resto do Canadá apenas se registrou um ou outro caso de viúvas, de primeira geração, responsabilizarem-se pela Festa em memória do falecido. No caso das filarmônicas, a de Laval era formada, maioritariamente, pela terceira geração.

A questão da diferença entre gerações e as tensões geradas sobre a organização da Festa ganhou destaque na Associação Portuguesa do Espírito Santo, em HochelagaMaisonneuve. Resolveu-se deixando os jovens celebrar a sua própria Festa, numa data diferente da Festa da Associação.

Relativamente à origem regional e à organização da Festa, três associações tinham um acentuado cunho terceirense: a Associação de Hochelaga, a de Aylmer e a do Centro Amigos Unidos. Em geral, era mais pronunciado o declínio da Festa terceirense a favor das Festas realizadas com vínculo à Igreja.

Nos anos 1990, constataram-se divisões entre os devotos em Gatineau, como previamente havia acontecido na cidade de Laval, nos anos 1970 e 1980, devido a conflitos entre as dioceses e as associações de leigos que fundaram as Festas e construíram as igrejas. 
Em Gatineau, a igreja ficou subordinada ao Centro do ponto de vista administrativo. Em Laval, não se chegou a resolver a tensão entre a Missão e a Associação que a criou. O padre preside o conselho econômico da Missão - como acontece com comissões de festas e irmandades nas igrejas de Toronto -, mas o conselho mede forças com a direção da Associação.

Em Gatineau, como resultado da divisão ocorrida nos anos 1990, a comunidade praticante portuguesa pode escolher entre duas igrejas para o culto. Na primeira fundada, administrada pelo Centro Comunitário Amigos Unidos, faz-se a Festa seguindo o conceito original de mordomia como entidade não regida pela igreja; na segunda, o padre fundador da igreja implementou mudanças na mordomia e no ritual para tornar a Festa mais conforme com o cânone religioso. Ele pôs em questão a promessa como base da fé e motivo de autosseleção, e a surpresa ou inspiração divina como meio de escolher o novo mordomo; e impôs ao cargo um cariz mais religioso do que cultural e social. Em ambos os casos, as Festas continuam a assegurar a sobrevivência das duas igrejas, como em Laval, Montreal e na província do Ontário, que tem o maior número de Festas do Espírito Santo no Canadá.

As Festas do Espírito Santo no Canadá são de natureza transnacional - viajaram do continente para os Açores e dos Açores para as Américas -, moldadas pela geografia, a passagem do mundo rural para o urbano, as identidades regionais e as fidelidades associativas. Mas, no país adotivo, continuam a ser orientadas para a comunidade local onde se inseriram, pelo que têm pouca visibilidade fora das comunidades luso-canadianas. Eram 87 as Festas no Canadá quando iniciamos a nossa pesquisa; atualmente são 78 aquelas de que temos conhecimento. 
Figuras 4 e 5 - Procissão da coroação em Anjou com Imperatriz e entrega das pensões em Sainte-Thérèse (2011).
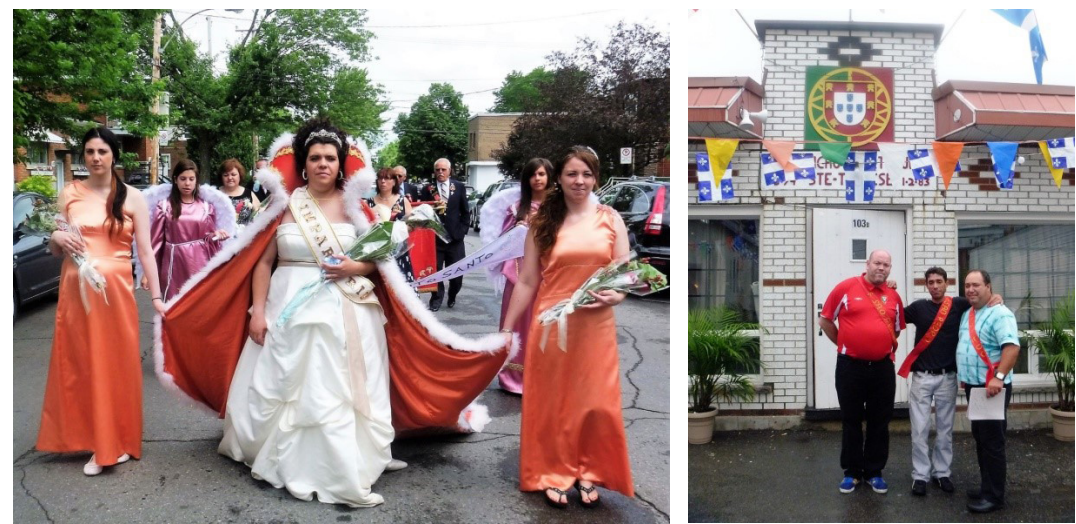

Fonte: Acervo de Ilda Januário.

\section{Considerações finais}

Após mapearmos as Festas do Espírito Santo no Rio Grande do Sul (Brasil) e Quebec (Canadá), percebemos que há um tema transversal que as atravessam, ou seja, sua função social está intimamente relacionada com a construção e reconstrução de identidades em diáspora. As comunidades se impõem no cenário local onde aquelas se realizam, e agrada-se ao Divino, buscando mediação entre o mundo dos homens e o espiritual - o do Espírito Santo, função simbólica primordial da festa.

No Rio Grande do Sul, não só descendentes de portugueses do continente ou das ilhas, mas também imigrantes de outras origens, como os italianos, celebram o Espírito Santo. Em Criúva e Vila Seca (Distrito de Caxias do Sul), por exemplo, locais cuja maioria da população é descendente de imigrantes italianos, ocorrem as Festas mais concorridas no Rio Grande do Sul, com grande mobilização da população, a partir das redes de vizinhança, parentesco, amizade, unindo a todos como devotos do Espírito Santo.

No Canadá, onde as Festas são ainda celebradas pela primeira geração de emigrantes que as criou, a questão da autenticidade é menos central, havendo sim uma maior preocupação com a identidade, a "democratização da mordomia" e uma mistura de práticas das várias ilhas que favorecem um maior envolvimento comunitário na Festa grande ou Bodo. 
As Festas são ocasiões privilegiadas para adorar o Espírito Santo e também para conviver, cooperar e partilhar. Trocas de tarefas, ofertas e donativos têm lugar no seio das famílias, entre amigos, associados e paroquianos tanto nas igrejas, como nas associações e nos circuitos festivos. As redes sociais são reforçadas: não só através da oração, decoração, organização, mas também ao cozinhar, comer, celebrar e limpar. E por serem unicamente açorianas no contexto migratório, também se tornaram marcadores identitários para os açor-norte-americanos (JANUÁRIO, 2019; LEAL, JANUÁRIO, MAPRIL, 2014).

Em destaque, nestas duas pesquisas, a busca da identidade pela Festa e da autenticidade da Festa, esta última mais marcada no Brasil devido à distância no tempo e no espaço da Festa original açoriana.

Ao encerrarmos este texto, deixamos aqui a despedida dos Tropeiros do Divino, em estrofe de música composta para a comemoração da passagem dos 250 anos da chegada do primeiro contingente dos casais de número açorianos no Rio Grande do Sul.

Os Tropeiros do Divino, Se despedem em cantoria,

Vão pela estrada afora, Repontando alegria. Por essa porta "entremo", ai Por esta mesmo "saimo", ai

(Tropeiros do Divino de Ivo Ladislau e Carlos Catuype)

\section{Referências}

ABREU, Martha. O Império do Divino: festas religiosas e cultura popular no Rio de Janeiro, 1830-1900. Rio de janeiro: Nova Fronteira; São Paulo: Fapesp, 1999.

A FESTA DO ESPÍRITO SANTO. Brasiliana iconográfica. Disponível em https://www. brasilianaiconografica.art.br/artigos/20192/a-festa-do-divino-espirito-santo Acesso em 21 nov.

CÔRTES, João Carlos Paixão. Folias do Divino. Porto Alegre: Proletra, 1983.

DREHER, Martin Norberto. Rostos da Igreja no Brasil Meridional. In: In: DREHER, 
Martin N. (org.). Populações rio-grandenses e modelos de igreja. Porto Alegre: Edições EST; São Leopoldo: Sinodal, 1998.

ETZEL, Eduardo. Divino: Simbolismo no Folclore e na Arte Popular. São Paulo: Livraria Kosamos Editorial, 1995.

GONÇALVES, José Reginaldo S.; CONTINS, M. Entre o divino e os homens: a arte nas festas do Divino Espírito Santo. Horizontes Antropológicos, Porto Alegre, ano 14, n. 29, p. 67-94, jan./jun. 2008. Disponível em http://www.scielo.br/pdf/ha/v14n29/a04v14n29 Acesso em 9 Fev. 2019.

GRAEBIN, Cleusa Maria Gomes. Sensibilidades em festa: celebrando o Espírito Santo no Rio Grande do Sul. Fênix - Revista de História e Estudos Culturais Janeiro/ Fevereiro/ Março/ Abril de 2012 Vol. 9 Ano IX nº 1. Disponível em: www.revistafenix.pro.br

HASTENTEUFEL, Pe. Zeno. O Espírito Santo na cultura luso-açoriana. In: HACKMANN, Geraldo Luiz Borges (org.). O Espírito Santo e a Teologia hoje. Porto Alegre: EDIPUCRS, 1998.

ISABELLE, Arsène. Viagem ao Rio Grande do Sul (1833-1834). Porto Alegre: Martins Livreiro Editor, 1983.

JANUÁRIO, Ilda. Irmãos e Irmãs na Coroa. As Festas do Espírito Santo no Canadá. Toronto: edição de autor, 2019. Disponível como e-book em: https://www.amazon.ca/Irm\%C3\%A3os$\mathrm{Irm} \% \mathrm{C3} \% \mathrm{~A} 3 \mathrm{~s}-\mathrm{Coroa}-\mathrm{Esp} \% \mathrm{C} 3 \%$ ADrito-Portuguese-ebook/dp/B081QPCVS6/ref=sr_1_1?k eywords $=$ irmaos + e + irmas + na + coroa\&qid $=1574964388 \& \mathrm{sr}=8-1$

LEAL, João. As festas do Espírito Santo nos Açores: um estudo de Antropologia Social. Lisboa: Dom Quixote, 1994.

LEAL, João et al. Festas do Espírito Santo. Disponível em http://festasdoespiritosanto.pt Acesso em 9 Fev. 2018.

LEAL, João. O culto do divino: migrações e transformações. Lisboa: Edições 70, 2017.

LEAL, João, Januário, Ilda \& Mapril, José. Holy Spirit Festas in Canada: A General Perspective. Paper presented at the final seminar of the project Holy Ghost Festas in North America: Ritual, Ethnicity, Transnacionalism. Lisbon, March 17-18, 2017.

NASCIMENTO, Mara Regina. Irmandades leigas em Porto Alegre: práticas funerárias e experiência urbana - séculos XVIII-XIX. Tese de doutorado. Pós-Graduação em História, UFGRS, Porto Alegre, 2006. Disponível em https://lume.ufrgs.br/handle/10183/8574 Acesso em 20 Nov. 2019.

PORTO ALEGRE, Aquiles. História Popular de Porto Alegre. Porto Alegre: Prefeitura Municipal, 1940.

SOUSA, Polina Macedo de. A festa do divino Espírito Santo: memória e religiosidade em Natividade-Tocantins. Porto Alegre, RS: Editora Fi, 2017. 


\section{Notas}

1 Professora e coordenadora Adjunta do Programa de Pós-Graduação em Memória Social e Bens Culturais da Unilasalle, Canoas, RS, Brasil. E-mail: cleusa.graebin@unilasalle.edu.br Responsável pela proposta do artigo e pela descrição das Festas do Espírito Santo no Rio Grande do Sul.

2 Pesquisadora no CRIA da Universidade Nova de Lisboa. Portugal. E-mail: ilda.januario@gmail.com Responsável pela descrição sobre as Festas do Espírito Santo no Quebec e revisora do artigo.

3 As pesquisas de Cleusa M. G. Graebin versam sobre açorianos no Rio Grande do Sul, festas do Espírito Santo, Ternos de Reis e Cavalhadas com apoio do CNPq e da FAPERGS.

4 As pesquisas de Ilda Januário foram feitas antes e dentro do âmbito do projeto Ritual, Etnicidade e Transnacionalismo: as Festas do Espirito Santo na América do Norte, coordenado por João Leal do CRIA - Centro em Rede de Investigação em Antropologia -, da Universidade Nova de Lisboa. Um website foi criado em equipa, em 2016, sobre as Festas no Canadá e Nova Inglaterra: festasdoespiritosanto.pt

5 No Rio Grande do Sul (Brasil), mais conhecida como Festa do Divino.

6 Entrada: expedições organizadas no período colonial brasileiro para aprezamento de indígenas e exploração de ouro e pedras preciosas.

7 Bandeira: expedições organizadas em caráter particular, tanto para aprezamento de indígenas a fim de negociá-los como escravos, como para prospectar metais e pedras preciosas.

8 Folias: Tratava-se de grupo de cantadores, tocadores de violão e de instrumentos de percussão, relacionados ou não a alguma Irmandade, os quais faziam visitação de fiéis, de porta em porta, em áreas urbanas ou rurais, portando a Bandeira do Divino, ilustrada com a Pomba que simboliza o Espírito Santo. A partir de louvações, recolhiam qualquer tipo de doação para a realização da Festa do Espírito Santo. Sobre esse tema ver: A FESTA DO ESPÍRITO SANTO. Brasiliana iconográfica. Disponível em https:// www.brasilianaiconografica.art.br/artigos/20192/a-festa-do-divino-espirito-santo Acesso em 21 nov. 2019.

9 Como eram chamados os primeiros contingentes transportados das ilhas dos Açores para o Sul do Brasil (Santa Cataria e Rio Grande do Sul). Os chamados casais eram formados por grupos de familiares. 